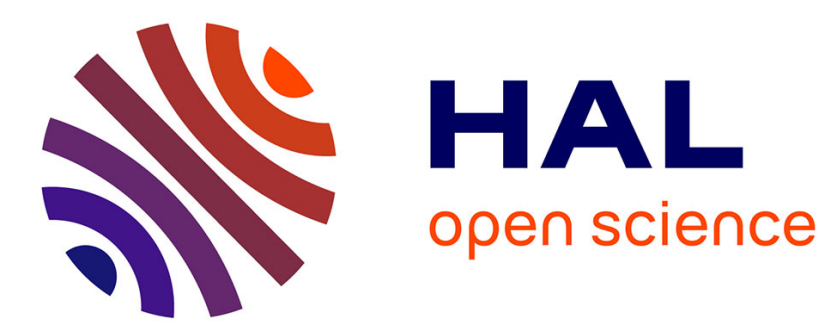

\title{
A space for innovation process acceleration, supporting collaborative citizens workshops
}

Nathalie Skiba, Laurent Dupont, Laure Morel, Claudine Guidat

\section{To cite this version:}

Nathalie Skiba, Laurent Dupont, Laure Morel, Claudine Guidat. A space for innovation process acceleration, supporting collaborative citizens workshops. 2012 18th International Conference on Engineering, Technology and Innovation, Jun 2012, Munich, Germany. pp.1-9, 10.1109/ICE.2012.6297646 . hal-01333514

\section{HAL Id: hal-01333514 \\ https://hal.science/hal-01333514}

Submitted on 17 Jun 2016

HAL is a multi-disciplinary open access archive for the deposit and dissemination of scientific research documents, whether they are published or not. The documents may come from teaching and research institutions in France or abroad, or from public or private research centers.
L'archive ouverte pluridisciplinaire HAL, est destinée au dépôt et à la diffusion de documents scientifiques de niveau recherche, publiés ou non, émanant des établissements d'enseignement et de recherche français ou étrangers, des laboratoires publics ou privés. 


\title{
A space for innovation process acceleration, supporting collaborative citizens workshops
}

\author{
Nathalie Skiba, Laurent Dupont, Laure Morel, Claudine Guidat \\ Université de Lorraine, ERPI, EA 3767, Nancy, F-54000, France, \\ \{nathalie.skiba, laurent.dupont, laure.morel,elisabeth.guidat\}@univ-lorraine.fr
}

\begin{abstract}
The city of Nancy (France) launched a Living Lab approach for the redevelopment of its eco-district. The first step of this project focuses on ideas exploration with the organization of participative workshops grouping citizens, technicians and politicians around the same table. The Environment and Methodology of Acceleration space or EMA space proposes ten theoretical functions adapted to realize collaborative workshops. The operational implementation of the EMA space functions is analysed according to two Living Labs characteristics - uses analysis and multidisciplinary collaborative work - and discussed. Organizers skills and political willingness are key aspects of the workshops success.
\end{abstract}

Keywords

Ideas exploration environment, collaborative work, uses analysis, urban project, citizens workshop

\section{Introduction}

The Lorraine Smart Cities Living Lab was designed to support public and private structures in their projects of high social and societal impact (mobility, city planning, self-directed learning, development of innovative economic activities, etc.) by providing tools, methods and multidisciplinary skills. It is made up of two entities: the university in charge of the scientific (ERPI laboratory) and operational part (NIT InoCité), and an incubator for innovative start-ups (Promotech).

The aim of this paper is to analyse the construction of an environment adapted to ideas exploration within an urban Living Lab experimentation. The project concerns the redevelopment of the train station area in the city of Nancy (north-east part of France), done through workshops (ateliers) known as the "Ateliers de la Fabrique". La Fabrique is the place where the workshops are set and is located in the heart of the train station area. The Ateliers de la Fabrique follow a participative approach through the organization of multidisciplinary workshops composed by citizens, technicians and politicians involved in the evolution of this part of the city. The goal is to favour ideas co-construction instead of participating to a debate on ideas. This aspect was already worked by Dupont who defined the ten theoretical core functionalities of an Environment and Methodology of Acceleration space or EMA space (Dupont, 2009).

As a result, we will demonstrate in this paper how the ten functions of the EMA space offer a framework suited for ideas exploration in a Living Lab approach and more precisely:

- How these functions help to identify and analyse uses of an urban place?

- How these functions facilitate collaborative work? 


\section{Relation to existing theories and work}

\subsection{Living Lab approach}

Living Lab approach is a new way to understand ecosystems by integrating uses in the design process since the fuzzy front end in order to increase the product ${ }^{1}$ adoption potential and accelerate innovation process. Living Lab concept emerged from an urban context: Mitchell ${ }^{2}$ explains that living environment (building, city, etc.) can be laboratories were to make experiments and work on real data. Cities and context (economy, energy, etc.) change very quickly because of information and communication technologies and Living Labs allow being reactive to this change.

Even if literature is full of Living Lab definitions: methodology (Eriksson et al., 2006), organizations (Almirall \& Wareham, 2008), open innovation ecosystem and partnership (European Commission, 2009), real life experimentation environment (Ballon et al., 2005), etc., we can note that basically a Living Lab approach is defined by three main characteristics:

- Uses analysis and integration in the design process: to make the concepts more relevant;

- Collaborative work: to maximize points of view, share knowledge, generate new ideas;

- Experimentation in real life context: to reduce the difference between anticipated uses and real uses.

Furthermore, some researchers have proposed what could be a Living Lab methodology. In our case, we decided to follow the Living Lab methodology in four steps defined by Pallot (Pallot, 2009) such as:

1. Exploration of ideas within multidisciplinary workshops;

2. Co-creation of specific ideas and elaboration of solutions;

3. Experimentation of the solutions in real life environment;

4. Evaluation of results and methodology.

The Ateliers de la Fabrique experimentation concerns the first step.

\subsection{EMA space}

In previous work, ERPI laboratory proposed a theoretical framework facilitating the innovation process and ideas co-construction: an Environment and Methodology of Acceleration space or EMA space (Dupont et al., 2010; Dupont, 2009). This space is made up of:

- A physical environment: a functional and friendly place accessible to everyone;

- A methodology: set of rules applied for good functioning of the space;

- An acceleration ability of the innovation process: thanks to the resources of the space (scientific and social researchers, collaborative tools, aided-decision software, users evaluation systems).

The EMA space aims to accelerate new ideas co-construction.

On the basis of nine observations of urban projects and a state-of-the-art and practices, Dupont identified ten functions that EMA space should fulfil when working on this specific type of project (Dupont, 2009); these functions constitute the theoretical framework of the EMA space:

1. Change the stakeholders' representation modes. "Citizens do not know that they know". They are having a uses experience; the issue of the workshops is to make politicians, technicians AND citizens understand the importance of this uses experience and bring them to collaborate (Dupont, 2009).

\footnotetext{
${ }^{1}$ In this paper we consider the broad sense of the term "product": object, service, environment, software, process, etc.

${ }^{2}$ Video interview: http://www.dailymotion.com/video/xffh66 william-j-mitchell-living-lab news
} 
2. Think in terms of use(r)s. In their work Champin and Prié show that the use / user relationship is not bi-univocal: a user may have several uses of one product and several users may have the same use of the same product (Champin \& Prié, 2002). Moreover to think in terms of uses helps to consider an ecosystem and not just the actors; users are identified once the uses are defined. To clarify this function we are working on uses and not on users.

3. Dispose of specific resources. Available resources help stakeholders to imagine themselves in a well-defined situation (simulation) and catch their reactions to define their needs, desires and preferences in a use situation.

4. Network the stakeholders and organisations. Network the stakeholders and organizations aims to create links between people, make them meet and work together, around the same global issue. Dupont proposes a model of distributed collaborative design, which combines advantages of collaborative design and the ones of distributed design, to serve networking in urban projects (Dupont et al. 2012).

5. Guarantee some methods of animation and project management. To be efficient a workshop should be prepared according to rigorous methods. Simply grouping participants around the same table will not produce good results. Every moment of the workshop should be prepared to bring the stakeholders to produce ideas and more than anything confront their vision.

6. Encourage pedagogy and exchanges between stakeholders. To facilitate collaboration between people of different cultures and languages, Boujut and Blanco show the efficiency of intermediary objects of conception or IOC (Boujut \& Blanco, 2003), which are intermediary representations of conception produced and shared by everyone.

7. Mobilize stakeholders all project long. Stakeholders must find a good interest, a motivation or feel that their work is given value to get involved all project long. Moments of mobilization must correspond to the panel's free time.

8. Produce specific behaviours. These behaviours give the opportunity to everybody to express themselves.

9. Encourage transparency in the aim of the project and in the decision-making process. Transparency allows giving value to stakeholders' participation and contributes to their mobilization.

10. Capitalize knowledge and ideas from stakeholders' integration. Knowledge about the project and about the methodology (process, methods, and tools) should be capitalized. Capitalization form is very important to make sure that it is reused for the continuation of the project or other projects. Sleeswijk Visser shows how communication support influences the way information is used (Sleeswijk Visser et al., 2007).

\subsection{Towards a framework to realize the exploration step of a Living Lab project}

As we can see, the EMA space was defined to focus on ideas co-creation process. As a result and based on the four steps methodology previously presented, we consider that the EMA space can offer an adapted framework to realize the first step of a Living Lab project by constructing an environment suitable for uses analysis and collaborative work.

We propose to test our proposal during the Ateliers de la Fabrique project. This project is lead by researchers of the university (NIT InoCité and ERPI) on the demand of public authorities to find answers to social and societal issues: mobility, diversity and attractiveness. It is an enablerdriven Living Lab project according to Nyström and Leminen's typology (Nyström \& Leminen, 2011). 


\section{Research framework}

\subsection{Workshops context and participation details}

The Ateliers de la Fabrique are divided into nineteen sessions, organized around seven topics (eco-mobility; living environment, urban practices and region identity; coherence between the three ages of the city; a better "live-together" and urban diversity; eco-construction and environmental quality; economical and social development; pilot block). Each topic will be discussed during two sessions, except for eco-mobility (three sessions) and pilot block (six sessions). The workshops took place during five months between February and June 2011 at the rate of one session of two hours every Thursday evening.

The workshops set always in the same place - La Fabrique - which is the ground floor of a building situated in the middle of the redevelopment project area. This room is big enough to welcome about 150-200 people and equipped with basic IT tools.

An exhibition illustrating the topic of the workshop session covers the walls of the room. As the topics alternate the setting is always changing and evolves with the work of the previous sessions, in order to maintain the knowledge acquired. La Fabrique is a lively place.

The workshop starts with a plenary session during which general observations made on the topic of the session are presented to every stakeholder.

Then, participants get separated into two or three private spaces, depending on the number of participants, in order to insure the quality of the collaboration. Ideal group size is about ten people. Special attention is placed on the good diversity of genders, ages and functions (professions).

Each space has the same equipment: working aid (white boards, paperboards, pictures, modular maps and mock-ups, computers, etc.), free expression means (post-its, white sheets of paper, colour pens, etc.), means to catch the exchanges within a group (audio recorder).

\subsection{Functioning of a session}

Stakeholders are welcomed by the organizers of the workshops and are invited to visit the exhibition which helps them to get basic knowledge about the subject they will work on. Note that exhibition can also be a support for some exercises.

The thirty minutes plenary session opens officially the atelier. Stakeholders are free to complete the presentation with commentaries.

Then, people works on exercises during 1:30 in groups and sub-groups in order to facilitate everyone's expression. Participants do not need technical knowledge to speak in the workshop: exercises are built in such a way that uses experience is enough to take part in the atelier.

As a result, the workshop procedure will help to identify stakeholders' needs, expectations, desires and preferences; establish a picture of actual and future uses and practices in the train station area; synthesize the results in a shared diagnosis.

\subsection{Experimentation protocol}

The experimentation protocol was constructed according to the ten EMA space functions detailed above: each function was implemented at an operational level. In order to evaluate if, as we suggest it in the introduction, the EMA space functions help to analyse uses and facilitate collaborative work, we will apply the following protocol:

1. Observation of the workshops' sessions, to evaluate the impact of the environment ( $\mathrm{La}$ Fabrique) on the quality of uses analysis (experiences and potential uses);

2. Distribution of a questionnaire to every participant during the final session, in order to evaluate the impact of the environment on the quality of collaborative work (Morel et al., 2010); 
3. Individual interviews to get participants' and coordinators' impression on the global participation process.

\section{Findings}

Thanks to our experimentation during the Ateliers de la Fabrique we can show that the ten EMA space functions constitute a suitable framework for uses analysis and collaborative work, and so support the ideas exploration part of a Living Lab project.

In order to present our findings, we have chosen to illustrate each of the ten functions by representative collected results or by management modes highlighted during the experimentation.

4.1 EMA space functions supporting the Ateliers de la Fabrique

\begin{tabular}{|c|c|c|c|}
\hline & EMA space functions & & Illustration during the Ateliers de la Fabrique \\
\hline 1. & $\begin{array}{l}\text { Change representation } \\
\text { modes }\end{array}$ & $=$ & $\begin{array}{l}\text { This change is triggered and encouraged by the } \\
\text { organizers, for example by mixing different } \\
\text { stakeholders profiles (citizens, technicians, } \\
\text { politicians) without presenting their functions. }\end{array}$ \\
\hline 2. & Think in terms of uses & $\approx$ & $\begin{array}{l}\text { Exercises make the participants think about the train } \\
\text { station area in their everyday life and the future they } \\
\text { would like for this area; anyway the workshops } \\
\text { observations showed that it is not easy for the citizens } \\
\text { to imagine themselves in twenty years. }\end{array}$ \\
\hline 3. & $\begin{array}{l}\text { Dispose of specific } \\
\text { resources }\end{array}$ & $=$ & $\begin{array}{l}\text { Material: means of catching (audio recorder, camera), } \\
\text { means of simulation (sounds and videos diffusion, 3D } \\
\text { and physical mock-ups), means of expression (post- } \\
\text { its, white boards, paperboards). } \\
\text { The questionnaire analysis reveals that every exercise } \\
\text { aid is perceived as pleasant by the stakeholders; } \\
\text { diversity and rotation of these aids is important to } \\
\text { create rhythm and dynamism during the sessions. } \\
78.7 \% \text { of the respondents think that exercises are } \\
\text { pleasurable which is important to make the } \\
\text { participants want to come back. }\end{array}$ \\
\hline 4. & Network & $=$ & $\begin{array}{l}\text { Members of citizens associations and professional } \\
\text { organizations attend to the workshops and can spread } \\
\text { ideas and methodologies in their own structures. } \\
\text { The ateliers are part of a global city project, } \\
\text { composed by several initiatives focusing on the eco- } \\
\text { district redevelopment project. }\end{array}$ \\
\hline 5. & Guarantee some methods & $=$ & $\begin{array}{l}\text { Exercises were built according to a sociological } \\
\text { approach, inspired by creativity principles. } \\
\text { Engineering science enssures the global approach of } \\
\text { the Ateliers de la Fabrique. }\end{array}$ \\
\hline 6. & $\begin{array}{l}\text { Encourage exchanges and } \\
\text { pedagogy }\end{array}$ & $=$ & $\begin{array}{l}\text { Most of the exercises are using IOC: adjustable } \\
\text { mock-ups and maps, facilitating the elaboration of a } \\
\text { proposition shared by the whole group. } 56.5 \% \text { of the } \\
\text { respondents declare that the exercises allowed them to } \\
\text { express their ideas easily. }\end{array}$ \\
\hline
\end{tabular}




\begin{tabular}{|c|c|c|c|}
\hline 7. & Mobilize participants & $\approx$ & $\begin{array}{l}\text { Personal communication by e-mails (it is time- } \\
\text { consuming but creates a strong relationship between } \\
\text { organizers and participants); despite that mobilization } \\
\text { decreases at the end of the project: less citizens ( } \sim 30 \\
\text { at the beginning and } \sim 20 \text { at the end) and no more } \\
\text { technicians and politicians). }\end{array}$ \\
\hline 8. & Produce specific behaviours & $=$ & $\begin{array}{l}\text { At the beginning of the workshops everybody gets the } \\
\text { same instruction: participants are presents as citizens } \\
\text { (politicians and technicians cannot restraint other } \\
\text { stakeholders' creativity with their technical } \\
\text { knowledge), to make sure that everybody is taking } \\
\text { part in the reflexion. } 84.8 \% \text { of the respondents } \\
\text { qualify the ateliers as a "moment of citizen } \\
\text { contribution" showing that the instruction was } \\
\text { understood and applied. } \\
90.6 \% \text { of the respondents consider that sub-groups } \\
\text { exercises helped them to speak during the workshop. } \\
\text { Atmosphere and framework of the space contribute to } \\
\text { the development of these specific behaviours. }\end{array}$ \\
\hline 9. & Encourage transparency & $\approx$ & $\begin{array}{l}\text { Citizens have a low visibility on decision criteria } \\
\text { (they do not know how their work will be used in the } \\
\text { rest of the project), but organizers and politicians } \\
\text { gave the insurance that the project will follow based } \\
\text { on the workshops' results. }\end{array}$ \\
\hline 10. & Capitalize knowledge & $=$ & $\begin{array}{l}\text { Audio catching of exchanges between stakeholders } \\
\text { within a group work. } \\
\text { Synthesis of the ateliers, distributed to the } \\
\text { participants during two report sessions (one } \\
\text { intermediary and one final) on CD's and booklet } \\
\text { (presentations of the plenary sessions, videos and } \\
\text { pictures from exercises, etc.). }\end{array}$ \\
\hline
\end{tabular}

Tableau 1: Operational results collected during the Ateliers de la Fabrique

\subsection{Discussion}

Three functions seem to be more difficult to realize: stakeholders' mobilization, transparency and reasoning in terms of uses.

The two first functions are rather linked to the political sphere:

- It was a political choice to limit the Ateliers de la Fabrique promotion among citizens; participants were targeted in the associative circles. Most of the participants attended to two workshop sessions (33.9 \% of the questionnaire respondents) but they declare at $26.6 \%$ that they are ready to attend as many workshops as necessary to lead a complete project and $29.7 \%$ declare that they would attend four sessions. Anyway only $11.3 \%$ of the respondents attended to four sessions and $27.5 \%$ attended to more than four sessions on nineteen. Opening participation to more citizens might have brought new participants in the course of the project and maintained the citizens' mobilization level. We formulate the following hypothesis about the lack of mobilization among technicians and politicians: participative approach is a kind of evaluation of their work and they feel uncomfortable with that. Taking part in the beginning of the workshops was a way to evaluate how "risky" this approach was for their work; considering that 
there was no danger, they lost personal interest in the project. Anyway we observe that politicians' presence have a negative effect on global collaboration: more stress within the group, less participation.

- Need of transparency emerged from free commentaries in questionnaires and interviews: participants are on the whole satisfied by the workshops methodology and think at $69.8 \%$ that they worked on rather useful questions for the future train station area, but are wondering what will happen next and how their work will be reused. It is important to show continuity between the four steps of the Living lab approach to keep them motivated. Even if organizers and politicians guarantee this continuity, citizens need to observe it by themselves. Game theory (or interactive decision theory) reveals that political strategy was not clearly defined at the moment of the ateliers restitution so it was not possible to show transparency.

Suitable environment is not enough to guarantee collaborative workshop's success; it is also dependent on political willingness. Beresford (Beresford, 2003) declares that "user involvement in research and evaluation is ultimately an ideological and ethical issue, not a technical one". He calls for a systematic development and evaluation of user involvement in research to identify its strengths and weaknesses and to support its most effective development. In our case, we study the impact of a neutral actor in the citizens participative approach: the university. It vouches for methodology and know-how and so limits the bias of the dual role of actor and decision-maker (even if university action depends on political decision) for a better citizens' involvement.

The third function was not totally fulfilled, obviously because of an under exploitation of $L a$ Fabrique resources helping participants to think forward: to imagine oneself in 2030 is not as efficient as to create a simulated framework of the situation in 2030 (diffusion of sounds, projection of pictures or videos, etc.)

Regarding the ten functions, we notice that they are linked to each other and must be thought together in their realization to be efficient. This link is carried out by the workshops organizers and their specific skills. Qualities of a good organizer, according to the questionnaire answers, are: spontaneity, humour and neutrality. Human aspect is the most important aspect of a workshop $(58.5 \%$ of the respondents think that it is very important for the quality of the workshop to be welcomed by the organizers and $63.1 \%$ find it very important to discuss with the other stakeholders before the beginning of the workshop) but it is also the most difficult to manage.

Urban domain often implies long term projects so acceleration ability of EMA space is difficult to measure but is possible to identify on several aspects:

- A pre-project was proposed by a city-planning agency; one of its members was interviewed and admitted that the workshops brought relevant data and new ideas: acceleration of relevant concepts construction;

- Some technicians working on the train station area project were not involved by the city-planning agency for the pre-project; by attending the workshops they catch information on the global project: acceleration of information access;

- When ideas were already imagined by one stakeholder, he can share his conclusions: acceleration of solutions development and test;

- Because of their success (collaboration, satisfaction of the participants, qualitative and quantitative uses data), the Ateliers de la Fabrique can be considered as good practice and serve as example for future participative approaches: acceleration of learning process on collaborative approach for local authorities.

On a global point of view, the Ateliers de la Fabrique are a success. 


\section{Conclusion and future prospects}

We saw that the EMA space constitutes a suitable framework for ideas exploration in a Living Lab approach. The operational implementation of the ten functions insures a good uses analysis and contributes to an efficient collaborative work. If EMA space is adapted to construct an exploration environment in a Living Lab approach, it should be completed by in situ experimentations to build decisions on real data and evidences.

EMA space management should be carried out by a neutral actor, vouching for specific organization know-how, to limit difficulties related to human and political aspects identified in the Ateliers de la Fabrique.

Based on the first results of the Ateliers de la Fabrique, the university has a project to design a permanent space aiming to improve and accelerate the innovation process. This space will be open to organizations (institutes, consultants), university (schools, laboratories) and private companies to realize their own projects. It aims to be a demonstrator of local competences.

Even if urban and industry sectors are quite different: issue, temporality, decision-making process, etc., we assume that EMA space functions and equipment stay valid for a company wishing to lead the exploration phase of an industrial Living Lab project. We can imagine that the ten functions could be weighted depending on the project context. Further research will be led in that sense.

\section{Acknowledgement}

We would like to thank Valérie Bretagne, Julien Hubert and Audrey Grandhomme - organizers of the Ateliers de la Fabrique - to let us observe these workshops and make precious comments.

\section{References}

Almirall, E; Wareham, J. (2008) Living Labs and open innovation: roles and applicability. The Electronic Journal for Virtual Organisations and Networks. Special issue on Living Labs, August 2008, no. 10, p. 21-46.

Ballon, P; Pierson, J; Delaere, S. (2005) Test and experimentation platforms for broadband innovation: examining European practice. Conference proceedings of 16th European regional conference by the International Telecommunications Society (ITS), Porto, Portugal, 4-6 September, 2005.

Beresford, P. (2003) User involvement in research: exploring the challenges. NTResearch, 2003, p. 36-46.

Boujut, J.-F; Blanco, E. (2003) Intermediary objects as a means to foster co-operation in engineering design. Computer Supported Cooperative Work, Netherlands, 2003, p. 205-219.

Champin, P.-A; Prié, Y. (2002) Modéliser l'utilisateur ou l'utilisation ? DVP, Brest, France, juillet 2002.

Dupont, L; Gholipour, V; Morel, L; Bignon, J.-C; Guidat, C. (2012) From urban concept to urban engineering: the contribution of distributed collaborative design to the management of urban projects. Journal of Urban Design, 2012.

Dupont, L; Guidat, C; Morel, L. (2010) EMA space: a collaborative workspace as collaborative urban ecosystem generator? Proceedings of the $16^{\text {th }}$ International Conference on Concurrent Enterprising. Lugano, Switzerland, 21-23 June 2010.

Dupont, L. (2009) Transfert du génie industriel au génie urbain : vers une approche collaborative des projets urbains. Thèse pour le doctorat de l'Institut National Polytechnique de Lorraine en Génie des Systèmes Industriels, Nancy, France, 2009.

Eriksson, M; Niitamo, V-P; Kulkki, S; Hribernik, K.A. (2006) Living Labs as a multi-contextual R\&D methodology. Proceedings of the 12th International Conference on Concurrent Enterprising: innovative products and services through collaborative networks, Milan, Italy, 26-28 June 2006.

European Commission (2009) Living Labs for user-driven open innovation: an overview of the Living Labs methodology, activities and achievements. Luxembourg: Office for Official Publications of the European Communities, January 2009, $57 \mathrm{p}$.

Morel, L; Guidat, C; Dupont, L; Bretagne, V; Revel, M; Bary, R. (2010) Concevoir des projets urbains en intégrant l'expertise d'usage : observation et évaluation des apports d'un espace de travail collaboratif pour améliorer la concertation publique. Rapport intermédiaire de recherche, Programme Concertation, Décision et Environnement du MEDAD, 4 mai 2010, 111 p. 
Nyström, A.-G; Leminen, S. (2011) Living Lab: a new form of business network. Proceedings of the $17^{\text {th }}$ International Conference on Concurrent Enterprising, Aachen, Germany, 20-22 June 2011.

Pallot, M. (2009) Les méthodes d'implication des utilisateurs dans le processus d'innovation : la démarche Living Lab comme écosystème de l'innovation ouverte. Séminaire SRI PACA, Marseille, France, 7 avril 2009.

Sleeswijk Visser, F. S; Van der Lugt, R; Stappers, P. J. (2007) Sharing user experiences in the product innovation process: participatory design needs participatory communication, 2007. 